University of Montana

ScholarWorks at University of Montana

2000

\title{
Bioethics Activities in Rural Hospitals
}

Ann Freeman Cook

University of Montana - Missoula, ann.cook@umontana.edu

Helena Hoas

University of Montana - Missoula, helena.hoas@umontana.edu

Katarina Guttmannova

Follow this and additional works at: https://scholarworks.umt.edu/psych_pubs

Part of the Psychology Commons

Let us know how access to this document benefits you.

\section{Recommended Citation}

Cook, Ann Freeman; Hoas, Helena; and Guttmannova, Katarina, "Bioethics Activities in Rural Hospitals" (2000). Psychology Faculty Publications. 7.

https://scholarworks.umt.edu/psych_pubs/7

This Article is brought to you for free and open access by the Psychology at ScholarWorks at University of Montana. It has been accepted for inclusion in Psychology Faculty Publications by an authorized administrator of ScholarWorks at University of Montana. For more information, please contact scholarworks@mso.umt.edu. 


\title{
Bioethics Activities in Rural Hospitals
}

\author{
ANN FREEMAN COOK, HELENA HOAS, and KATARINA GUTTMANNOVA
}

\section{Background}

Hospital ethics committees have evolved as a response to complicated legal, ethical, and social dilemmas that accompany modern medicine. In the United States, their growth has been augmented by Joint Commission for the Accreditation of Healthcare Organizations (JCAHO) standards and the Patient SelfDetermination Act. ${ }^{1}$ There appears to be an implicit presumption that all clinical ethics consultation practices are relatively similar. ${ }^{2}$ Finally, there is heightened awareness of the needs for quality standards and assessment of the outcomes of ethics consultations. ${ }^{3}$

Program emergence has been less well substantiated in rural settings, and the research area for this project provides some justification for that status. The identified states - Montana, North Dakota, South Dakota, Alaska, eastern Washington, and northwest Minnesota-have an estimated population of 2,844,299 people and encompass approximately 886,000 square miles. That land mass is roughly equivalent in size to all the states situated east of the Mississippi River. By far the greater portion of this area, approximately 802,000 square miles, meets the criteria for frontier counties. ${ }^{4}$ Such counties have population densities of less than six people per square mile and residents experience the full impact of rural isolation and remoteness. Winters are long, mountain passes can prove treacherous, and the limited interstate highway system forces reliance on secondary roads. The region is characterized by a limited number of physicians, counties with neither hospitals nor physicians, and low per capita income. Nearly $30 \%$ of the rural populations live in areas considered to be medically underserved. ${ }^{5}$ One of three counties in this geographic area does not have a hospital. Fifty-five percent of the counties are served by single hospitals. The most remote counties are typically served by one or two physicians. There are entire counties that report no physicians in residence. Tertiary care centers serve very large geographic areas; for some residents, travel to a tertiary care center might involve a trip of more than 500 miles.

The rural hospital's economic constraints are complicated by the inability to reach the economies of scale realized by larger hospitals, rural-urban payment differentials ${ }^{6}$ and long underserved, high-risk populations. The rates of poverty and disability in rural areas are higher than those experienced in urban areas. ${ }^{7}$

This project has been supported by a grant from the Charles E. Culpeper Foundation (now part of the Rockefeller Brothers Fund). We are grateful to Glenn McGee, Ph.D., for his collaboration with respect to research activities, to participating hospitals throughout the High Mountains High Plains Project Area and to staff assistants Pam Diedrich and Catherine Ipsen. 


\section{Bioethics Activities in Rural Hospitals}

The costs associated with a complicated, uninsured case can compromise the health of an entire community. If a rural hospital or clinic closes, jobs are lost and patients may not have easy access to other healthcare settings. However, institutional decisions relative to cost containment prove difficult because services must be denied to someone who is well known, who trusts the rationer, and with whom the rationer envisions a shared future. Cost-containment issues shadow the patient when health complications require treatment in distant, tertiary care settings. The cost savings achieved via an early discharge may be mildly problematic for an urban patient who lives minutes away from a medical center. For the rural patient, who may live 20 miles down an unpaved road and 70,80 , or hundreds of miles from the hospital, the consequences can be devastating.

\section{Description of the Survey}

\section{Purpose}

The survey was designed to accomplish four tasks: (1) document the status of bioethics committees or other bioethics mechanisms in a multistate rural demonstration area, (2) investigate the functions of existing bioethics committees, (3) investigate the perceived need for bioethics committees or services among hospitals that do not currently have such entities, and (4) identify bioethics resources that meet the needs of persons who live in rural areas. This information is required in order to build a foundation for subsequent research with respect to bioethics in rural areas. This empirical base could lead to models that meet identified needs.

\section{Methods}

The geographic area involved in this project is served by 216 acute care hospitals (freestanding psychiatric and rehabilitation hospitals were excluded from the sample). Administrators of the 216 acute care hospitals received a letter describing the High Mountains High Plains Rural Bioethics Project, a copy of the survey, and a request to provide information detailing the hospital's approach to bioethics services. The survey was based on a model developed by Glenn McGee of the University of Pennsylvania Center for Bioethics. All respondents answered questions regarding hospital size, occupancy rates, number of employees, presence of an ethics committee, needs for bioethics services, roles and membership (or potential roles and membership) of ethics committees, benefits and obstacles of such committees, and technical assistance and training needs. For hospitals without bioethics committees, a two-page, 16-item survey was provided. A series of 28 items expanded the survey completed by hospitals with bioethics committees. Those items included questions about the structure, procedures, function, activities, and effectiveness of the committees, as well as their training and consultation practices. Since every survey included the name of the hospital and a primary contact, project staff were able to recontact hospital personnel if any of the information provided required clarification. Approximately $12 \%$ of the respondents were recontacted to verify information provided in the survey. 
One hundred seventeen surveys $(54.16 \%)$ were analyzed. Sixty-seven percent of the respondents were hospital administrators. Thirteen percent of the respondents were directors of nursing and $9.2 \%$ of the respondents were members of ethics committees. The results of this survey suggest that many issues are of concern to all hospitals in this area rather than to specific states. Comparisons of Montana, North Dakota, and South Dakota showed no significant differences in the distributions relative to the presence or absence of bioethics committees, the presence or absence of JCAHO accreditation, or the identification of roles and issues.

\section{Approach to the Data}

The number of licensed, acute care beds and the average daily occupancy rate were used as proxies to determine hospital size. For most analyses, hospitals were assigned to one of three groups: $0-25$ beds, $26-50$ beds, and 51 or more beds. Forty-five percent of the hospitals have fewer than 25 beds and $70.9 \%$ have 50 or fewer beds. In general, hospitals are small; only $7 \%$ have more than 150 beds. Although the survey did not ask if the hospital provided long-term care, $14 \%$ of the respondents indicated that their hospitals routinely provide both acute care and long-term care in the same setting and with the same staff.

\section{Results}

\section{The Status of Bioethics Committees in Rural Areas}

Data indicated that $58.8 \%$ of the hospitals responding to this survey did not have bioethics committees or a similar mechanism to resolve bioethical dilemmas. Logistic regression analysis suggested a predictive relationship among the size of the hospital, the presence of an ethics committee, and JCAHO accreditation. Small hospitals were less likely to have bioethics committees $(R=0.304$, $\mathrm{p}<.01)$ and less likely to hold JCAHO accreditation $(\mathrm{R}=0.365, \mathrm{p}<.01)$. Overall, $63.9 \%$ of hospitals participating in the survey did not have JCAHO accreditation. Fifty percent of all surveyed hospitals had neither bioethics committees nor JCAHO accreditation. Among hospitals with 25 or fewer beds, 90.6\% lacked accreditation and 85.2\% lacked ethics committees.

There was a relationship between JCAHO accreditation and the presence of a bioethics committee $(\varphi=0.523, \mathrm{p}<.01)$. Generally, it was the larger hospitals and hospitals with JCAHO accreditation that reported the existence of bioethics committees. Seventy-five percent of the hospitals with bioethics committees reported over 50 beds; all of the hospitals with more than 100 beds reported the existence of bioethics committees. Seventy-six percent of the hospitals with JCAHO accreditation also had bioethics committees.

There was a positive relationship $(\mathrm{r}=.321, \mathrm{p}=.036)$ between the size of the hospital and the number of people serving on the committee. As the hospital size increased, committee membership increased as well. Although dominated by physicians and other healthcare professionals, membership included administrators, clergy, physicians, nurses, community representatives, and others. There was a positive relationship between the size of the hospital and the number of physicians serving on the ethics committee $(r=.620, p<.01)$. As the 
size of the hospital increased, the numbers of physicians serving on the committee increased. The hospital size was positively related to the numbers of attorneys serving on the committee $(\mathrm{r}=.536, \mathrm{p}=.015)$. This trend was not uniform, however. Fifty-eight percent of hospitals with more than 50 beds did not have any attorney on the committee.

Approximately half of the existing committees (59.2\%) met on a monthly basis. The rest of the committees met on an irregular basis. Some committees, although identified as "existing," had not met for several years. Ostensibly, a request for an ethics consultation can be made by a variety of people. Physicians were most consistently identified (89.8\%), but hospital staff $(87.8 \%)$, social worker $(83.7 \%)$, family member $(87.8 \%)$, patient $(85.7 \%)$, and nurse $(85.7 \%)$ were also identified as persons able to request a consultation. However, given the irregular meeting schedule and the paucity of training specific to bioethics, it is difficult to determine the extent to which hospital staff, patients, and family members know services exist and would feel comfortable requesting a referral.

\section{Functions of Bioethics Committees in Rural Areas}

A sizable body of literature has focused on bioethics committees as vehicles for education, policy development, case consultation, research, and patient advocacy. ${ }^{8}$ Bioethics committees in rural areas perform these functions, but in limited capacities. In general, respondents from hospitals without ethics committees ranked patient advocacy as the most important role and research as the least important role. Respondents from hospitals with ethics committees indicated the greatest percentage of time on average was allocated to education $(29.24 \%)$, followed by policy development $(22.96 \%)$, case consultation $(19 \%)$, research $(13.9 \%)$, and patient advocacy. It is difficult to quantify the percentage of time allocated to patient advocacy because the identification of a bioethics committee as either a hospital administration committee or a medical staff committee had a significant impact on the time allocated to patient advocacy. Sixty-five percent of existing ethics committees were described as hospital administration committees. Twenty-six percent were identified as medical staff committees. Medical staff committees spend significantly less time on patient advocacy $(\mathrm{T}=-3.772, \mathrm{p}<.01)$. There may also be an underlying relationship between the size of the hospital and the roles that bioethics committees play. As the size of the hospital increased, provision of case consultation increased $\left(\mathrm{r}_{\mathrm{s}}=.508\right.$, $\mathrm{p}<.01$ ). Case consultation was less likely to be provided in hospitals with 25 or fewer beds. Only $28.6 \%$ of the committees formally evaluate activities. Hospital experiences in performing each of the traditionally ascribed roles are as follows:

Advocacy. When provided a list of 14 topics, respondents indicated that the issues most frequently discussed by bioethics committees included: (1) advanced directives/end of life, (2) protecting patient autonomy, (3) patient competency, and (4) improving communication between patients and clinicians. As the size of the hospital increased, discussion relative to patient-physician relations and patient autonomy also increased. "End-of-life care" was the most important clinical issue and most important procedural issue facing bioethics committees. However, fewer than $50 \%$ of the hospitals with ethics committees (44.9\%) regularly informed patients or family members of the existence of the committee. 
Certain issues were very rarely or never discussed in bioethics committees. Examples of these issues included: physician-assisted suicide, distributing scarce goods and services, cost-containment issues, research trials or studies, and new technologies or services. Physician-assisted suicide was identified as the least discussed issue and $80 \%$ of the respondents indicated it was never discussed.

Policy. Previous studies suggest that the responsibility to initiate, review, or revise institutional policies for making decisions related to patient care is a central criteria for health ethics committee success. ${ }^{9}$ Respondents were given a list of five policy issues and asked to describe the role that bioethics committees had in terms of formulating, reviewing, or evaluating each policy. The policy issues included brain death, DNR orders, withholding/withdrawing lifesustaining treatment, advance directives, and required request for organ donation. For purposes of this analysis, hospitals were grouped according to more than 50 beds, or 50 beds or fewer. Although they were able to complete other parts of the survey, $12 \%$ of the respondents provided no information describing involvement in policy issues.

Forty-nine percent of the respondents indicated the ethics committee reviewed policies regarding DNR orders and $44.9 \%$ reviewed policies relating to withholding or withdrawing life-sustaining treatment. Review of other policy issues was much reduced. Committees were less likely to either formulate or evaluate policies. Only $33.5 \%$ of committees had a role in formulating policies and only $32.5 \%$ had a role in evaluating policies. There was particularly little involvement in policies related to organ donation. Over $40 \%$ of the committees had no role in formulating, reviewing, or evaluating policies related to required request for organ donation.

Education. Fifty-seven percent of the respondents identified education as the most successful activity. However, $16.3 \%$ of the respondents indicated community or staff education was the least successful activity. Ninety-six percent of the committees that meet on a monthly basis provide education to the committee members. The education typically involves a seminar, a guest speaker, or a yearly conference. None of the respondents identified the use of any formal educational materials, such as a curriculum or an ethics committee manual. Most education efforts are restricted to the committee. Fifty-nine percent of the existing committees provided some level of community education, and typical formats included a yearly luncheon, an annual program, or a workshop or seminar. However, respondents did not indicate the content provided in such educational opportunities, and it was not clear if the educational opportunities were specifically related to bioethics or if they had a more general health promotion focus. Seventy-three percent of existing committees provide staff education. Such education typically involves orientations, seminars, in-service, or noon conferences. More research is needed in order to identify the content area specific to staff education.

\section{Perceptions of Need for Bioethics Services}

Even though hospitals without bioethics committee could identify the benefits obtained from committees, $69 \%$ of the respondents indicated that a bioethics committee was not needed in their facility. The designation of "unnecessary" 
appears related to the inadequacies of the committee model. Time constraints $(41.4 \%)$, the size of the hospital (31\%), and lack of support from administration and physicians $(17.1 \%)$ were cited as inhibitors to committee development. However, there was strong interest in both receiving educational resources and participating in a bioethics project. Ninety-six percent of the respondents from hospitals with ethics committees identified at least one resource that would be helpful. Eighty-five percent of the respondents from hospitals without ethics committees identified at least one resource that would be helpful. Examples of resources included monthly articles, educational materials, policy development updates, independent study material, and models for bioethics services. Only $4 \%$ of the respondents from hospitals with ethics committees said they would not be interested in participating in a bioethics-related project. Among hospitals without ethics committees, $72.9 \%$ indicated potential interest in a project that would provide technical assistance and training in the area of bioethics.

\section{Discussion}

Respondents to this survey expressed interest in providing services that help practitioners, patients, and family members deal with difficult issues. But "bioethics" as understood in rural areas may be different from bioethics as understood and practiced in urban and academic settings. Home for spring break, the young college student announced he was taking fencing. "At last" replied the Montana rancher, "a college is teaching something practical."

In rural areas, social, geographic, and economic barriers complicate the use of the traditional multidisciplinary committee. Ethics committees are envisioned as time-consuming and difficult to sustain. Committees require members who are knowledgeable about the issues, spend time developing expertise, and cultivate an ability to apply ethical theory. ${ }^{10}$ An adequate budget, increased numbers of meetings, and a chairperson with training in the area of bioethics positively influence the success of hospital ethics committees. In rural areas, budgets are tightly restricted, meetings are irregular, and persons with graduate degrees in clinical or theological ethics are rarely available. The predominant model of an ethics consultant, a sort of "beeper" ethicist available to different hospital units, is inconsistent with the realities of rural life. Montana and Alaska do not even have their own state medical schools. Medical staffs are small, on-call schedules are demanding, and requests to serve on more than one hospital committee are numerous. Only 29 hospitals in the entire sample $(n=117)$ have bioethics committees that meet on a monthly basis.

From a social perspective, the familiarity that exists in small towns also complicates committee development. A committee with a membership of physicians, administrators, nurses, social workers, clergy, and community members may jeopardize confidentiality and intimidate both healthcare providers and family members. Finally, in order to meet the generally accepted guidelines for clinical consultation, ${ }^{11}$ outside expertise would have to be arranged. The need for outside expertise, however, implies a certain local incompetence; when outside experts are brought into rural communities, their authority and the activities that accompany their authority are somewhat suspect. The provision of bioethics services, the qualifications of providers, and the distribution of power are unsettling and highly political issues. ${ }^{12}$ Rural hospitals might find interventions such as small multidisciplinary teams or inter-institutional teams 
and networks more useful than multidisciplinary committees. The small teams could meet on a more regular basis and develop education activities to support competency in the area of bioethics. However, more research is needed in order to understand how those teams should be formed and supported and whether such teams are an effective substitute for formal committees.

\section{Limitations of Roles}

Committee roles are influenced by factors that include the size of the hospital, the designation of the committee as medical staff or hospital administration, the frequency of meetings, and the number of years the committee has existed. The majority of bioethics committees provide limited leadership in the development, review, or evaluation of policies. Although end-of-life care was identified as both the most important clinical and most important procedural issue, committees that serve small hospitals (50 or fewer beds) generally had no role in the development, evaluation, or review of a policy related to that issue. Discussions pertinent to cost containment, distribution of scarce goods and services, physician-assisted suicide, and new techniques or rules were almost nonexistent. Although such discussions may be difficult, the economic constraints of rural hospitals and the rapidly evolving healthcare system suggest that some issues (e.g., cost containment and distribution of scarce goods and services) are unavoidable. As the managed care movement intensifies, the integration of corporate and community norms with the goals of patient care may become issues that rural hospitals must face. Given the fact that the majority of hospitals lack committees or other mechanisms to resolve ethical issues, it is important to learn how organizational ethics interfaces with policy decisionmaking in rural areas. The limited efforts with respect to documentation and evaluation make it difficult to analyze activities and obtain any empirical understanding of the policy function.

Patient advocacy has been consistently identified as an important role for bioethics committees. Indeed, the central purpose of ethics consultation is one of improving the process and outcomes of patients' care. ${ }^{13}$ However, patient advocacy was not cited as one of the "most successful" activities, and it is difficult to assess the extent to which bioethics committees support or understand that role. The ability to request a consultation, for example, does not indicate who actually requests consultations, why such a request is made, whether there is a process for requests, or what kind of outcome was achieved. Three factors - the infrequency of committee meetings, the lack of patient knowledge with respect to available services, and the fact that medical staff committees appear to minimize the advocacy role-suggest that the patient advocacy role may be limited. Previous studies indicate that health ethics committees rarely hear patients' and families' concerns directly. ${ }^{14}$ The disparity between health practitioners' expectations and patient concerns may be substantial. ${ }^{15}$

Case consultation was identified as one of two least successful activities, and respondents did not identify access to case consultation as a primary benefit of a bioethics committee. There may be several reasons for this finding. In communities with a network of interwoven values and relationships, decisionmaking based on the value-free, objective knowledge of consultants may be far from ideal. When, for example, consultation is envisioned within Agich's consultation models of watcher, witness, teacher, and consultant, ${ }^{16}$ the problems 


\section{Bioethics Activities in Rural Hospitals}

are numerous. The watcher who is disinterested and objective, the witness who maintains the quality of a stranger, the teacher who offers a discipline-restricted orientation, and the consultant with academic expertise present realities and values distant from rural life. Such models do not provide the focus, the continuity, or the long-term educational initiatives that are important in rural communities.

\section{Conclusions}

The identification of the bioethics issues that are most relevant in rural settings could: (1) help committees or other mechanisms delineate primary activities, (2) identify resources that support those activities, and (3) guide the development of other models of or approaches to services. In rural areas, the most problematic issues relate to end-of-life care, patient autonomy, patient competency, and patient-physician relations. Although not quite as common, discussions also involve differences of opinion among patients and caregivers and confidentiality.

The services that are provided may depend on practice settings. Bioethical dilemmas are not limited to an inpatient, acute care facility. They are encountered in office visits, home visits, and long-term care settings that in rural areas appear to be intimately linked with acute care systems. Practice settings also have a definite impact on issues such as the perception of need for a committee, development of educational resources, and identification of policy issues.

The practice setting is also relevant to culture and ethnicity. Montana has seven Native American reservations, North Dakota has four reservations, South Dakota has eight reservations, and Alaska has 500 Native villages. A dominant Euro-western bioethical perspective may be inconsistent with Native values, ${ }^{17}$ underscoring the need for cultural sensitivity.

The limited literature with respect to bioethics in rural areas implies that urban solutions can be readily adapted to rural environments. In reality, the healthcare dilemmas that develop in rural areas are colored by spaces and distances almost unimaginable to most city dwellers. Different roles are appropriate for different settings, and the advocacy of particular models must reflect context, method, and normative outlook. ${ }^{18}$ Merely transplanting urban models, guidelines, standards, and training requirements into resource-limited rural healthcare scenes appears to be inadequate. Identifying resources, disseminating materials, and developing linkages among similarly sized institutions could be useful interventions. Materials that can be disseminated via computer digital media and other distance technologies could be particularly helpful in rural areas of the country.

Identifying and developing the models that meet the needs of rural communities is not unlike composing a fugue. Although based on one theme, a fugue is played in different voices and different keys, occasionally at different speeds or upside down or backward. ${ }^{19}$ The succession of voices provide rhythmic, harmonic, and melodic contrasts. "There are, to be sure, standard kinds of things to do-but not so standard that one can merely compose a fugue by formula." 20 Attention to the bioethics of healthcare is an important issue in rural communities. But the doing and the voices, the contrasts and countersubjects, transcend the parameters of any one model and require a foundation built on time and place, function and need. 


\section{Ann Freeman Cook, Helena Hoas, and Katarina Guttmannova}

\section{Notes}

1. Omnibus Budget Reconciliation Act of 1990. Pub.L.No. 101-508, (4206, 104 Stat.) 1388-115 (codified at 42 U.S.C. $1395 \mathrm{cc}(\mathrm{f})$ ).

2. Fox M, McGee G, Caplan A. Paradigms for clinical ethics consultation practice. Cambridge Quarterly of Healthcare Ethics 1998;7:308-14.

3. Fox E, Arnold RM. Evaluating outcomes in ethics consultation research. Journal of Clinical Ethics 1996;7:127-38; Anzia DJ, LaPuma J. Quality care and clinical ethics. Quality Review Bulletin 1992;Jan.:21-3; Danis M. Should hospital ethics committees study themselves? Journal of Clinical Ethics 1994;5:159-62.

4. Research and Training Center on Rural Rehabilitation Services. Rural Facts: An Update on the Demography of Rural Disability. Missoula, Mont.: University of Montana, 1998:1-4.

5. von Reichert C. Access to healthcare and travel for birthing: Native American-white differentials in Montana. Geoforum 1995; 26:297-308.

6. See note 5, von Reichert, 1995; Nelson W, Pomerantz A. Ethical issues in rural health and hospitals. In: Friedman E, ed. Choices and Conflict: Explorations in Healthcare Ethics. Chicago: American Hospital Publishers, 1992:156-63.

7. Nord M. Rural Conditions and Trends 7 (1997):37-9; McNeil, J. Americans With Disabilities: 199192. Washington, D.C.: U.S. Government Printing Office, 1993.

8. Griener G, Storch J. The educational needs of ethics committees. Cambridge Quarterly of Healthcare Ethics 1994;3:467-77; Fletcher J, Siegler M. What are the goals of ethics consultation? A consensus statement. Journal of Clinical Ethics 1996;7:122-6. Arnold R, Youngner S, Aulisio M, et al. Core Competencies for Health Care Ethics Consultation. Glenview, Ill.: American Society for Bioethics and Humanities, 1998.

9. Scheirton L. Measuring hospital ethics committee success. Cambridge Quarterly of Healthcare Ethics 1993;2:495-504; Scheirton L. Determinants of hospital ethics committee success. HEC Forum 1992;4:342-59; Nelson W, Pamerantz A. Ethical issues in the rural healthcare setting. In: Friedman E, ed. Choices and Conflict: Explorations in Healthcare Ethics. Chicago: American Hospital Publishers, 1992:156-63.

10. See note 8, Griener, Storch 1994.

11. See note 2, Fox, McGee, Caplan 1998; see also note 8, Fletcher, Siegler 1996; Tulsky JA, Fox E. Evaluating ethics consultation: framing the questions. 1996; Journal of Clinical Ethics 7(2):109-15; Agich G. Clinical ethics: a role theoretic look. Journal of Social Science E Medicine 1990;30:389-99.

12. Agich G. Authority in ethics consultation. Journal of Law, Medicine E Ethics 1995;23:273-83.

13. See note 8, Fletcher, Siegler 1996:125.

14. Jacobson J, Francis L, Battin M, Green D, et al. Dialogue to action: lessons learned from some family members of deceased patients at an interactive program in seven Utah hospitals. Journal of Clinical Ethics 1997;8:359-71.

15. Gerteis M. What patients really want. Health Management Quarterly 1993;15(3):2-6.

16. See note 11, Agich 1990.

17. Carrese J, Rhodes L. Western bioethics on the Navajo reservation: benefit or harm? JAMA 1995; 274:826-9.

18. See note 2, Fox, McGee, Caplan 1998.

19. Hofstadter D. Godel, Escher, Bach: An Eternal Golden Braid. New York: Vintage Books, 1979:9.

20. See note 19, Hofstadter 1979:9. 